\title{
Editorial
}

\section{Are Somatostatin or Its Synthetic Analogues Helpful in Reducing Pancreatic Fistula?}

\author{
Eliane Angst Beat Gloor \\ Department of Visceral Surgery and Medicine, Inselspital, University of Bern, Bern, Switzerland
}

\section{Key Words}

Octreotides $\cdot$ Risk factors $\cdot$ Selection bias

Pancreatic surgery is associated with a high morbidity. One of the most frequently seen major complications is a pancreatic leak or fistula [1]. The incidence of pancreatic leaks, irrespective of its severity, is around $30-40 \%$, which is the most important factor contributing to the overall morbidity [2]. Adjusting surgical techniques such as anastomosing the pancreatic remnant to the stomach instead of jejunum, or applying pancreatic duct stenting have not decreased fistula rates $[3,4]$. Both the prophylactic and therapeutic use of somatostatin or its synthetic analogues have been analyzed in uncontrolled and randomized controlled trials with contradicting outcomes, and data have been submitted to meta-analyses $[2,5]$.

In this edition of Digestive Surgery, Droeser et al. analyzed retrospectively whether the incidence of pancreatic fistula was lower after administration of octreotide within $24 \mathrm{~h}$ of surgery. The study question is of substantial interest given the impact of pancreatic fistulas and routine administration of an expensive drug (octreotide) on healthcare costs. The authors used a prospectively collected, single-center database of 684 patients who underwent pancreatic resection for benign and malignant disease. Some 133 patients developed a postoperative pan- creatic fistula (19.4\%) of which 55 patients were excluded from the analysis, because they received octreotide later than $24 \mathrm{~h}$ after surgery. Of the remaining 78 patients, 22 were treated with octreotide. Comparing the 22 patients with octreotide with the 56 patients without, the authors found that the lipase activity was not influenced by octreotide and that length of postoperative hospital stay was not different. In addition, patients receiving octreotide developed more grade $\mathrm{B}$ and $\mathrm{C}$ fistula. Therefore the authors concluded that octreotide was not helpful in prevention or treatment of pancreatic fistula.

How should we interpret this study? The administration of prophylactic octreotide was based on the surgeon's decision and was not started preoperatively as in the published randomized controlled trials. In other words, the attending surgeon decided to administer octreotide based on certain risk factors for pancreatic fistulas such as the texture of the pancreas, type and duration of surgery, nutritional status of the patient, blood loss, secondary diagnoses, ASA score and tumor stage. Therefore, fistula rates may differ between patient groups based on selection bias, which is strong in this type of retrospective analysis. Moreover, only 22 patients received octreotide which is by far not sufficient to exclude that the above risk factors were not responsible for the higher rate of grade $\mathrm{B}$ and $\mathrm{C}$ fistula in the octreotide group. This study therefore does not support either using or abandoning octreotide and is in good company with the other publications.

\section{KARGER \\ Fax +4161306 1234}

E-Mail karger@karger.com

www.karger.com
(C) 2013 S. Karger AG, Basel

0253-4886/12/0296-0492\$38.00/0

Accessible online at:

www.karger.com/dsu
Beat Gloor

Inselspital, BHH D

Freiburgstrasse

$\mathrm{CH}-3010$ Bern (Switzerland)

E-Mail beat.gloor@insel.ch 
The question whether somatostatin or its analogues administered routinely during and after pancreatic surgery reduces pancreatic fistulas has recently been analyzed by The Cochrane Collaboration ${ }^{\circledR}[6]$. Some 19 studies were included in the analysis. It is worth noting that $17(89 \%)$ of the included studies were rated at 'high risk of bias' hence questioning the methodological quality of the included studies and as a result the meta-analysis itself. Furthermore, the proportion of clinically significant fistulas was not mentioned in most studies. The authors showed that the incidence of 'pancreatic fistula' was lower in the somatostatin analogue group. Looking at clinically significant fistulas, there was no difference between patients receiving somatostatin analogues or no somatostatin. The authors concluded that somatostatin analogues may reduce perioperative complications but do not reduce perioperative mortality [6].
It is important to critically review the scientific evidence and current standards of care, especially at the present current time of limited resources. Based on the available studies, the routine use of somatostatin or its analogues can neither be recommended nor abandoned for patients undergoing pancreatic resection. However, if the arguments in favor of somatostatin analogues are so weak, omission of this rather expensive drug may be more appropriate than using it routinely in pancreatic surgical practice.

\section{Disclosure Statement}

The authors have no conflicts of interest to disclose.
References

Can Somatostatin or Its Synthetic Analogues Reduce Pancreatic Fistula?
1 Alexakis N, Sutton R, Neoptolemos JP: Surgical treatment of pancreatic fistula. Dig Surg 2004;21:262-274.

2 Connor S, Alexakis N, Garden OJ, Leandros E, Bramis J, Wigmore SJ: Meta-analysis of the value of somatostatin and its analogues in reducing complications associated with pancreatic surgery. Br J Surg 2005;92:10591067.

3 Xiong JJ, Altaf K, Mukherjee R, et al: Systematic review and meta-analysis of outcomes after intraoperative pancreatic duct stent placement during pancreaticoduodenectomy. Br J Surg 2012;99:1050-1061.
4 Yang SH, Dou KF, Sharma N, Song WJ: The methods of reconstruction of pancreatic digestive continuity after pancreaticoduodenectomy: a meta-analysis of randomized controlled trials. World J Surg 2011;35:2290-2297.

$\checkmark 5$ Gans SL, van Westreenen HL, Kiewiet JJ, Rauws EA, Gouma DJ, Boermeester MA: Systematic review and meta-analysis of somatostatin analogues for the treatment of pancreatic fistula. Br J Surg 2012;99:754-760.

6 Gurusamy KS, Koti R, Fusai G, Davidson BR: Somatostatin analogues for pancreatic surgery. Cochrane Database Syst Rev 2012; 6:CD008370. 